\title{
Plantas medicinais utilizadas em comunidades rurais de Oeiras, semiárido piauiense
}

OLIVEIRA, F.C.S. ${ }^{1 *}$; BARROS, R.F.M. ${ }^{2}$; MOITANETO, J.M. ${ }^{3}$

${ }^{1}$ Universidade Federal do Piauí, Av. Universitária,1310, Campus Ininga, CEP: 64.049-550, Teresina-Brasil *Carlaoliveira11@gmail.com 2 Universidade Federal do Piauí, Centro de Ciências da Natureza, Departamento de Biologia, Campus Ministro Petrônio Portela, Ininga, CEP: 64049-550, Teresina-Brasil ${ }^{3}$ Universidade Federal do Piauí, Centro de Ciências da Natureza, Departamento de Química, Campus Ministro Petrônio Portela, Ininga, CEP: 64049-550, Teresina-Brasil jmoita.ufpi@gmail.com

RESUMO: O estudo foi realizado no período de fevereiro de 2007 a maio de 2008, em vinte e uma

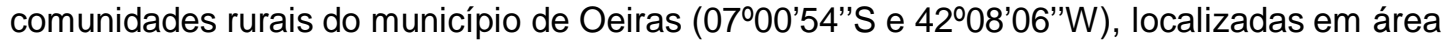
de transição vegetacional Caatinga/Cerrado, onde predomina a Caatinga. Objetivou-se conhecer as plantas tradicionalmente utilizadas pela população com fins terapêuticos. As coletas botânicas seguiram metodologia usual e os exemplares identificados foram incorporados ao acervo do Herbário Graziela Barroso (TEPB). Como procedimento metodológico realizou-se entrevistas semi-estruturadas com formulários padronizados a 20 moradores indicados por líderes comunitários locais como pessoas de reconhecido saber, que acompanharam as coletas. As espécies citadas foram agrupadas em de 17 categorias de acordo com a Organização Mundial de Saúde (OMS). Os dados quantitativos foram obtidos através do cálculo da Importância Relativa (IR) para cada espécie e do Fator de Consenso dos Informantes (FCI). Assim, identificou-se 167 etnoespécies, distribuídas em 59 famílias botânicas e 143 gêneros, sendo 65,86\% nativas. As famílias com maior representatividade em número de espécies foram a Leguminosae (28) e a Euphorbiaceae (18). Os gêneros mais representativos foram Croton L. (9), Senna Mill. (5), Jatropha L. e Solanum L. (4). Caesalpinia ferrea Mart., Ximenia americana L., Myracrodruon urundeuva Allem. e Lippia alba L., obtiveram os maiores valores de IR de 1,79; 1,86; 1,21; 1,14; respectivamente. Salienta-se a elevada frequência de usos terapêuticos destas espécies, concentradas no tratamento dos transtornos do sistema respiratório (56 espécies) e das doenças infecciosas intestinais, hepáticas e helmintíases (65), sendo gripe e diarréia as doenças mais citadas. A folha é a parte do vegetal mais utilizada na medicina caseira local ( $31,5 \%$ dos casos) e as formas de preparo mais utilizadas são a decocção (32,2\% dos casos) seguida por infusão $(23,8 \%)$. Estes dados possibilitam inferir que os moradores das comunidades rurais possuem conhecimento acerca das plantas utilizadas como medicinais, especialmente as nativas.

Palavras-chave: etnomedicina, etnobotânica, Oeiras/PI, plantas medicinais

\begin{abstract}
Medicinal plants used in rural communities from Oeiras Municipality, in the semi-arid region of Piauí State (PI), Brazil. This study was performed between February 2007 and May 2008 in twenty-one rural communities from Oeiras Municipality (07.00'54'S and $42^{\circ} 08^{\prime} 06^{\prime \prime} \mathrm{W}$ ) located in a transition area of Caatinga/Cerrado vegetation, where Caatinga predominates. The aim was to know the plants traditionally used for therapeutic purposes by the population. The botanical harvests followed the usual methodology and the identified specimens were incorporated into the collection from the Herbarium Graziela Barroso (TEPB). As methodological procedure, semi-structured interviews by using standardized forms were done with 20 dwellers indicated by local community leaders as people presenting notorious knowledge and who accompanied the harvests. The cited species were grouped into 17 categories, according to the World Health Organization (WHO). Quantitative data were obtained by calculating the relative importance $(\mathrm{RI})$ for each species and the informant consensus factor (ICF). We identified 167 ethnospecies, distributed into 59 botanical families and 143 genera, from which $65.86 \%$ were native. The most representative families in number of species were Leguminosae (28) and Euphorbiaceae (18). The most representative genera were Croton L. (9), Senna Mill. (5), Jatropha
\end{abstract}

Recebido para publicação em 09/01/2009

Aceito para publicação em 25/04/2010

Rev. Bras. Pl. Med., Botucatu, v.12, n.3, p.282-301, 2010. 
L. and Solanum L. (4). Caesalpinia ferrea Mart., Ximenia americana L., Myracrodruon urundeuva Allem. and Lippia alba L. had the highest RI values: 1.79, 1.86, 1.21 and 1.14, respectively. It must be emphasized the high therapeutic use of these species, mainly for the treatment of respiratory system disorders (56 species) and intestinal, hepatic and helminthic infectious diseases (65), from which flu and diarrhea were the most cited. The leaf is the most used plant part in the local folk medicine (31.5\% of cases). The most frequently used preparation procedures are decoction (32.2\% of cases) and infusion (23.8\%). These data allow inferring that dwellers of rural communities have knowledge about the plants used as medicinal, especially native ones.

Key words: ethnomedicine, ethnobotany, Oeiras/PI, medicinal plants

\section{INTRODUÇÃO}

As populações humanas convivem com uma grande diversidade de espécies vegetais, desenvolvendo maneiras particulares de explorá-las para distintas finalidades, usando-as como alternativa de sobrevivência. Dentre estas, do repertório cultural, destaca-se o conhecimento sobre a utilização de plantas para fins terapêuticos.

Os estudos sobre o uso das plantas para fins medicinais desenvolvidas por Amorozo \& Gely (1988), Milliken \&Albert (1996), Gonçalves \& Martins (1998), Rêgo (1998), Castellucci et al. (2000), Rodrigues \& Carvalho (2001), Amorozo (2002), Coutinho (2002), Franco \& Fontana (2002), Ritter et al. (2002), Nunes et al. (2003), Medeiros et al. (2003), Macêdo \& Ferreira (2004), Pereira et al. (2004), Fuck et al. (2005), Sousa \& Felfili (2006), Azevêdo \& Silva (2006), Borba \& Macedo (2006) e Pinto et al. (2006) demonstram crescente interesse acadêmico pela medicina tradicional, especialmente após o reconhecimento de que a base empírica pode, muitas vezes, ter comprovação científica e de que a análise da exploração do ambiente pelos povos tradicionais fornece subsídios para estratégias de manejo e uso adequado de determinados ambientes.

Encontram-se no estado do Piauí, trabalhos com plantas medicinais realizados por Berg \& Silva (1985), que compõem uma contribuição para o conhecimento da flora local; Abreu (2000), da diversidade dos recursos vegetais do cerrado, empregados pelos quilombolas Mimbó, no município de Amarante; Franco \& Barros (2006), com as plantas medicinais usadas pela comunidade Quilombola Olho D'água dos Pires, município de Esperantina; Santos et al. (2007), de plantas medicinais empregadas pela população de Monsenhor Gil. Vieira (2008) pesquisou as plantas empregadas para fins medicinais no Quilombo dos Macacos, São Miguel do Tapuio, destacando o fator de consenso e a importância relativa das etnoespécies estudadas.

Oeiras detém um rico patrimônio histórico, são seculares tradições culturais e religiosas, consideradas a cidade mais antiga do Piauí, sede da primeira capital, destacando-se no roteiro turístico do Estado, especialmente devido às festividades religiosas. Desta forma, o presente estudo enfoca as relações etnobotânicas de comunidades rurais deste município, de forma pioneira, como forma de registro e valorização da cultura tradicional nativa, por meio do uso atribuído à vegetação pela população.

Oeiras, cidade de notável riqueza histórica, beleza arquitetônica e tradição religiosa, considerada a mais antiga do estado, faz parte do roteiro turístico do Estado. Os principais atrativos do município são as Igrejas de Nossa Senhora da Vitória e Nossa Senhora do Rosário, o monumento de Nossa Senhora da Vitória e a Casa de Pólvora. Os eventos populares de maior destaque de Oeiras e do Piauí são a Festa de Passos, Procissão do Fogaréu e Semana Santa, ao reunir pessoas de todo o Estado e de outras regiões do País. Os fiéis decoram o altar de casa com alecrim-de-passos ( Lippia sp) e carregam ramalhetes durante a procissão. Grande parte dos fiéis veste roupas da cor lilás, em homenagem ao santo, especialmente para o pagamento de promessas. Após a procissão, é celebrada missa na igreja Nossa Senhora da Vitória (Oliveira, 2008).

Crendices e superstições são bastante difundidas no imaginário popular local. A lenda mais amplamente disseminada é a da existência de um carneiro de ouro que à noite cruza a cidade correndo $e$ quem o vir fica rico. Outra é a visitação de duas marcas em uma rocha, denominadas localmente de Pé-de-Deus e Pé-do-Diabo, que se assemelham a pegadas humanas. Segundo a tradição, ao visitá-los, ao colocar o pé sobre uma das marcas (Pé-de-Deus), sempre se consegue o encaixe perfeito e, na outra, joga-se pedras. Salienta-se, igualmente, que na frente da maioria das residências encontram-se Jatropha gossypiifolia L. (pião-roxo) plantados para espantar mal olhado e trazer bons presságios (Oliveira, 2008).

A presente pesquisa objetivou identificar as etnoespécies utilizadas como fitoterápicos no tratamento de enfermidades, em comunidades rurais de OeirasPiauí.

\section{MATERIAL E MÉTODO}

Oeiras compreende uma área de 2.719,53 $\mathrm{km}^{2}$, a vegetação é caracterizada pela transição Cerrado/Caatinga, predominando a caatinga

Rev. Bras. Pl. Med., Botucatu, v.12, n.3, p.282-301, 2010. 
arbustivo-arbórea (CEPRO, 2000). O clima tropical semiárido quente, a duração do período seco é de sete a oito meses, a temperatura varia entre $26^{\circ} \mathrm{C} \mathrm{e}$ $40^{\circ} \mathrm{C}$, estando à sede do município a altitude de 166 $\mathrm{m}$ acima do nível do mar. Os rios Canindé, Itaim e Tranqueira, e as lagoas da Feitoria e Tapera são os principais cursos d'água (CEPRO, 1992).

O estudo foi realizado em locais com baixo nível de antropização e que apresentavam maior preservação da vegetação nativa, através de dados obtidos junto a Prefeitura Municipal de Oeiras. Foram pesquisadas vinte e uma comunidades da zona rural

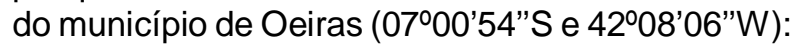
Araçá, Brionia, Buriti do Rei, Canto do Buriti, Carolina, Cepisa, Chapada das Panelas, Contentamento, Exu, Fazenda Extrema, Fazenda Frade, Ingazeiras, Ipueiras, Malhada da Onça, Onça, Sete Galhos, Soares, Sossego, Várzea da Cruz, Vereda Grande e Vila Cannaã. A denominação Fazenda Extrema e Fazenda Frade abrangem a extensão da propriedade privada e também é a denominação local dada à área de moradia ao entorno destas.

$\mathrm{Na}$ estrutura produtiva, sobressai-se a agricultura com a produção de milho, feijão, mandioca, arroz e banana e o extrativismo para a obtenção de lenha, madeira em tora e a palha da carnaúba (CEPRO, 1992).

A coleta de material botânico e de dados etnobotânicos foram efetuadas no período compreendido entre fevereiro de 2007 e maio de 2008 , quinzenalmente nos meses chuvosos e mensalmente nos meses secos, através de caminhadas aleatórias ou em locais previamente definidos, seguindo o procedimento rotineiro de campo sugerido por Mori et al. (1989). A identificação botânica foi realizada a partir da análise da morfologia externa do material, consulta à literatura, por comparação com o material incorporado ao acervo do Herbário Graziela Barroso (TEPB), da Universidade Federal do Piauí (UFPI) e, posteriormente, encaminhado a especialistas para confirmação e/ou determinação. O material testemunho encontra-se depositado no acervo do TEPB. O sistema de classificação adotado foi o de Cronquist (1981), exceto para a família Leguminosae que obedeceu a Judd et al. (1999). Os sites IPNI (www.ipni.org) e mobot (www.mobot.mobot.org) foram consultados para conferência da grafia dos nomes das espécies e abreviaturas dos nomes dos autores.

Os dados etnobotânicos foram obtidos mediante entrevistas semi-estruturados (Albuquerque et al., 2008), com a aplicação de formulários padronizados, com perguntas abertas e fechadas a 20 moradores da região, com idade superior a 35 anos e que residiam no local a mais de 25 anos. Para escolha dos informantes-chave foi questionado em cada comunidade quem era profundo conhecedor da vegetação local e dos usos e com estes foram realizadas entrevistas. Apenas dez desses acompanharam as turnês de coleta e um mesmo informante acompanhou as excursões de campo em duas localidades, por conhecê-las profundamente: Exu e Chapada das Panelas. Nas entrevistas foram registrados dados gerais dos entrevistados (nome, idade, profissão, tempo de residência no local e estado civil) e informações relacionadas às plantas citadas como os usos, preparos, partes utilizadas e nomes vernaculares.

A Importância Relativa (IR) de cada espécie foi calculada conforme a proposta de Bennett \& Prance (2000), através da fórmula IR $=N S C+N P$, onde $N S C=$ número de sistemas corporais tratados por uma determinada espécie (NSCE), divididos pelo número de sistemas corporais tratados pela espécie mais versátil (NSCEV); NP= número de propriedades atribuídas a uma determinada espécie (NPE), dividido pelo número total atribuído à espécie mais versátil. $O$ valor máximo da IR obtida por uma espécie será 2.

O Fator de Consenso dos Informantes ( $\mathrm{FCl}$ ) foi calculado através da fórmula $\mathrm{FCl}=$ nar - na /nar 1, adaptada de Trotter \& Logan (1986), onde: nar = somatório de usos registrados por cada informante para uma categoria; na = número de espécies indicadas na categoria.

O valor máximo do $\mathrm{FCl}$ é 1, quando há consenso completo entre os informantes dentro da categoria medicinal para uma doença específica.

As doenças citadas pelos informantes locais foram agrupadas em 13 categorias, listadas pela Organização Mundial de Saúde (OMS, 2000), a impotência sexual; gravidez, parto e puerpério; doenças do sangue e órgãos hematopoiéticos; doenças do sistema ósteo-muscular e tecido conjuntivo; neoplasias e doenças virais; transtornos do sistema cardiovascular; transtornos do sistema nervoso; doenças de pele e do tecido subcutâneo; transtorno do sistema digestório; doenças endócrinas, nutricionais e metabólicas; inflamações e dores em geral; sintomas e sinais gerais e transtornos do sistema sensorial (visão).

\section{RESULTADOE DISCUSSÃO}

O universo dos entrevistados (35\% mulheres e 65\% homens) nasceu no Piauí, sendo que moram há mais de 25 anos na área. Do total, foi identificado que $70 \%$ situam-se na faixa etária entre 55 e 70 anos e $30 \%$ estão entre 35 e 54 anos. Constatou-se que para $75 \%$ dos entrevistados a renda familiar mensal atinge no máximo um salário mínimo, $25 \%$ tem renda inferior a um salário mínimo e, apenas $5 \%$ tem renda de dois salários mínimos. Em $55 \%$ dos domicílios moram seis pessoas, nos $45 \%$ restantes moram até cinco indivíduos. Quanto à escolaridade, 55\% não são alfabetizados, $40 \%$ possuem Ensino Fundamental

Rev. Bras. Pl. Med., Botucatu, v.12, n.3, p.282-301, 2010. 
e apenas $5 \%$ concluiu o Ensino Médio. Observou-se que $75 \%$ declaram-se católicos e apenas $25 \%$ evangélicos.

As atividades desenvolvidas pelas famílias centraram-se na agricultura de subsistência, onde o milho, o feijão, a mandioca, o arroz e a banana estão entre os principais cultivos e na criação de pequenos animais para autoconsumo. Dados que corroboram aos apresentados para o Estado por Franco (2005). Presenciou-se, secundariamente, que os serviços do lar são direcionados para as mulheres e a caça e o extrativismo desenvolvidos pelos homens.

As entrevistas permitiram identificar 167 espécies empregadas como fitoterápicos. Elas estão distribuídas em 143 gêneros e 59 famílias botânicas (Tabela 1), cujas famílias mais representativas em número de espécies foram Leguminosae (28), seguida por Euphorbiaceae (18), Lamiaceae, Solanaceae (8), Anacardiaceae (7), Cucurbitaceae, Malvaceae, Poaceae (6), Malpighiaceae, Bignoniaceae (5), Arecaceae, Boraginaceae, Cactaceae, Combretaceae e Verbenaceae (4), que em conjunto perfizeram $61,2 \%$ do total. Resultados semelhantes quanto ao número de espécies das famílias Leguminosae e Euphorbiaceae foram referidos no Piauí por Abreu (2000) no quilombo Mimbó no município de Amarante; por Franco \& Barros (2006) no Quilombo Olho D'água dos Pires, município de Esperantina; por Chaves (2005) em Cocal e por Vieira (2008) no Quilombo dos Macacos em São Miguel do Tapuio. Os gêneros mais representativos foram Croton L. (9), Senna Mill. (5), Jatropha L. e Solanum L. (4).

TABELA 1. Etnoespécies utilizadas como medicinais em 21 comunidades rurais de Oeiras(Piauí - Brasil), no ano de 2007 e 2008. TEPB: número de registro (Herbário Graziela Barroso/UFPI). Indicação. FP- forma de preparo: 1- decocto; 2- infusão; 3- lambedor; 4- garrafada; 5- uso tópico; 6- bochecho; 7- suco; 8- in natura; 9banho; 10- emplastro; 11- sumo; 12- supositório; 13- inalação; 14- molho; PU: parte utilizada: Planta inteira (in); Folhas (fo); Casca (cs); Raiz (ra); Caule (ca); Frutos (fr); Flores (fl); Semente (se); Látex (la); Caule subterrâneobulbo (bu) IR: importância relativa; il: identificado no local. * Espécies nativas.

\begin{tabular}{|c|c|c|c|c|}
\hline TAXA & TEPB & Indicação (FP) & PU & IR \\
\hline \multicolumn{5}{|l|}{ Amaranthaceae } \\
\hline $\begin{array}{l}\text { Gomphrena demissa Mart.* } \\
\text { (ervanço) }\end{array}$ & 23.550 & $\begin{array}{l}\text { inflamação do útero } \\
\text { e ovários (1) }\end{array}$ & ra & 0,21 \\
\hline $\begin{array}{l}\text { Indet. } \\
\text { (as) }\end{array}$ & 23.642 & febre (2) & fo & 0,21 \\
\hline \multicolumn{5}{|l|}{ Amaryllidaceae } \\
\hline $\begin{array}{l}\text { Habranthus sylvaticus Herb.* } \\
\text { (cebola-brava) }\end{array}$ & 23.09 & dores em geral (1) & $\mathrm{fl}$ & 0,21 \\
\hline
\end{tabular}

\section{Anacardiaceae}

Anacardium occidentale L. * (caju)

23.884

Myracrodruon urundeuva Allem. * (aroeira)

23.883

(cajá)

23.923

S. purpurea L.

(seriguela)

S. tuberosa Arruda*

(umbu)

23.886 pancada, febre (2)

disenteria (4)

sangramento da

gengiva (6)

gastrite (7)

inflamações em geral,

inflamação do útero e ovários, gastrite,

úlcera, aborto (4)

útero baixo (9)

cólicas estomacais (2)

diarréia (3)

ferimento, câncer (5)

diarréia, anemia (2)

dor de dente (5)

diarréia (1)

dor no corpo, aborto (1)
CS

CS

0,86

CS

$\mathrm{fr}$

CS
CS

CS

1,21

CS

CS

CS

CS

fr $\quad 0,50$

fo $\quad 0,21$

fo $\quad 0,21$ 
TABELA 1. Etnoespécies utilizadas como medicinais em 21 comunidades rurais de Oeiras(Piauí - Brasil), no ano de 2007 e 2008. TEPB: número de registro (Herbário Graziela Barroso/UFPI). Indicação. FP- forma de preparo: 1- decocto; 2- infusão; 3- lambedor; 4- garrafada; 5- uso tópico; 6- bochecho; 7- suco; 8- in natura; 9banho; 10- emplastro; 11- sumo; 12- supositório; 13- inalação; 14- molho; PU: parte utilizada: Planta inteira (in); Folhas (fo); Casca (cs); Raiz (ra); Caule (ca); Frutos (fr); Flores (fl); Semente (se); Látex (la); Caule subterrâneobulbo (bu) IR: importância relativa; il: identificado no local. * Espécies nativas.

...continuação

\begin{tabular}{|c|c|c|c|c|}
\hline TAXA & TEPB & Indicação (FP) & PU & IR \\
\hline \multicolumn{5}{|l|}{ Annonaceae } \\
\hline \multirow{2}{*}{$\begin{array}{l}\text { Annona squamosa L.* } \\
\text { (ata) } \\
\text { Rollinia leptopetala R. E. Fr.* } \\
\text { (bananinha) }\end{array}$} & 23.864 & $\begin{array}{c}\text { diarréia (2) } \\
\text { apendicite, vômito (1) }\end{array}$ & $\begin{array}{l}\text { fo } \\
\text { se }\end{array}$ & 0,36 \\
\hline & 23.866 & coceira (2) & ra & 0,21 \\
\hline \multicolumn{5}{|l|}{ Apiaceae } \\
\hline $\begin{array}{l}\text { Anethum graveolens L. } \\
\text { (endro) }\end{array}$ & il. & diarréia infantil (1) & se & 0,21 \\
\hline $\begin{array}{l}\text { Coriandrum sativum L. } \\
\text { (coentro) }\end{array}$ & 23.917 & $\begin{array}{c}\text { calmante, cólica menstrual (2) } \\
\text { hérnia (2) } \\
\text { cicatrização de } \\
\text { umbigo }(10)\end{array}$ & $\begin{array}{l}\text { se } \\
\text { se } \\
\text { ra }\end{array}$ & 0,71 \\
\hline $\begin{array}{l}\text { Daucus carota L. } \\
\text { (cenoura) }\end{array}$ & il. & $\begin{array}{l}\text { menstruação } \\
\text { irregular }(7)\end{array}$ & ra & 0,21 \\
\hline \multicolumn{5}{|l|}{ Arecaceae } \\
\hline $\begin{array}{l}\text { Astrocaryum vulgare Mart. }{ }^{*} \\
\text { (tucum) }\end{array}$ & 24.035 & dores nas costas (1) & $\mathrm{fr}$ & 0,21 \\
\hline $\begin{array}{l}\text { Orbignya phalerata Mart.* } \\
\text { (babaçu) }\end{array}$ & il. & $\begin{array}{c}\text { diarréia (2) } \\
\text { ferimento (5) }\end{array}$ & $\begin{array}{l}\text { se } \\
\text { se }\end{array}$ & 0,43 \\
\hline $\begin{array}{l}\text { Mauritia flexuosa L. f.* } \\
\text { (buriti) }\end{array}$ & il. & queimaduras (10) & se & 0,21 \\
\hline $\begin{array}{l}\text { Copernicia prunifera (Mill.) H.E. Moore* } \\
\text { (carnaúba) }\end{array}$ & 24.033 & afrodisíaco (4) & ra & 0,21 \\
\hline \multicolumn{5}{|l|}{ Asclepiadaceae } \\
\hline $\begin{array}{l}\text { Calotropis procera (Aiton) R. Br. } \\
\text { (flor-de-seda) } \\
\text { Cryptostegia madagascariensis Bojer ex }\end{array}$ & 23.871 & reumatismo (7) & la & 0,21 \\
\hline $\begin{array}{l}\text { Decne. } \\
\text { (caça-de-amor; cipó-preto) }\end{array}$ & 23.432 & hérnia (5) & la & 0,21 \\
\hline
\end{tabular}

\section{Asteraceae}

Acanthospermum hispidum DC. *

(cabeça-chata)

23.480

pedras na vesícula (1) pneumonia (1) hipertensão, febre

Acmella ciliata (Kunth) Cass. *

(agrião; jambre)

23.482

inflamações em geral (2)

Bidens pilosa $\mathrm{L}$.

(carrapicho-de-agulha)

23.484

pneumonia, gripe (1)

dor de dente (5)

Emilia sonchifolia (L.) DC.*

(pincel)

23.472

hepatite, icterícia (2)

infecção urinária (1)

$\begin{array}{cc}\text { fo } & 0,43 \\ \text { ra, ca } & \\ \mathrm{fl} & 1,0 \\ \mathrm{fo} & \\ \mathrm{fl} & \\ \mathrm{fr} & 0,64 \\ \mathrm{ra}, \mathrm{fo} & \end{array}$

Pectis oligocephala Sch. Bip.*

(alecrim)

23.481

pancada (10)

fo $\quad 0,21$

gripe (3)

in $\quad 0,21$ 
TABELA 1. Etnoespécies utilizadas como medicinais em 21 comunidades rurais de Oeiras(Piauí - Brasil), no ano de 2007 e 2008. TEPB: número de registro (Herbário Graziela Barroso/UFPI). Indicação. FP- forma de preparo: 1- decocto; 2- infusão; 3- lambedor; 4- garrafada; 5- uso tópico; 6- bochecho; 7- suco; 8- in natura; 9banho; 10- emplastro; 11- sumo; 12- supositório; 13- inalação; 14- molho; PU: parte utilizada: Planta inteira (in); Folhas (fo); Casca (cs); Raiz (ra); Caule (ca); Frutos (fr); Flores (fl); Semente (se); Látex (la); Caule subterrâneobulbo (bu) IR: importância relativa; il: identificado no local. * Espécies nativas.

...continuação

\begin{tabular}{|c|c|c|c|c|}
\hline TAXA & TEPB & Indicação (FP) & PU & IR \\
\hline \multicolumn{5}{|l|}{ Bignoniaceae } \\
\hline $\begin{array}{l}\text { Jacaranda brasiliana (Lam.) Pers.* } \\
\text { (coroba) }\end{array}$ & 23.389 & mordida de cobra (1) & $\mathrm{ca}$ & 0,21 \\
\hline $\begin{array}{l}\text { Mansoa alliacea (Lam.) A.H. Gentry } \\
\text { (alho-de-cura) }\end{array}$ & 23.374 & $\begin{array}{l}\text { hipertensão (2) } \\
\text { verme, gripe (3) }\end{array}$ & $\begin{array}{l}\text { fo } \\
\text { fl }\end{array}$ & 0,64 \\
\hline $\begin{array}{l}\text { Memora pedunculata (Vell.) Miers* } \\
\text { (cipó-preto) }\end{array}$ & 23.379 & $\begin{array}{l}\text { gripe, verme }(3) \\
\text { diarréia }(2)\end{array}$ & $\begin{array}{l}\text { cS } \\
\text { cS }\end{array}$ & 0,57 \\
\hline $\begin{array}{l}\text { Tabebuia impetiginosa (Mart.) Standl.* } \\
\text { (pau-d'arco-roxo) }\end{array}$ & 23.380 & $\begin{array}{c}\text { limpar o sangue (4) } \\
\text { coceira (9) } \\
\text { dor no corpo }(1) \\
\text { gripe (3) }\end{array}$ & $\begin{array}{l}\text { CS } \\
\text { CS } \\
c S \\
c S\end{array}$ & 0,86 \\
\hline $\begin{array}{l}\text { T. ochracea (Cham.) Stan dl.* } \\
\text { (pau-d'arco-amarelo) }\end{array}$ & 23.375 & $\begin{array}{l}\text { inflamações em } \\
\text { geral (2) }\end{array}$ & cs & 0,29 \\
\hline \multicolumn{5}{|l|}{ Bixaceae } \\
\hline $\begin{array}{l}\text { Bixa orellana L.* } \\
\text { (urucum) }\end{array}$ & 23.874 & $\begin{array}{l}\text { colesterol alto (2) } \\
\text { diabetes (2) }\end{array}$ & $\begin{array}{l}\text { se } \\
\text { se }\end{array}$ & 0,36 \\
\hline
\end{tabular}

Pseudobombax sp. * (barriguda)

23.878

reumatismo, hérnia (2)

cs $\quad 0,43$

Boraginaceae

Cordia rufescens A. DC. *

(grão-de-galo)

23.876

dor no figado, dor nos rins (1)

ra $\quad 0,29$

doenças de criança,

Heliotropium indicum L. inflamações em geral (1)

(crista-de-galo)

inflamação do útero

e ovários (4)

diarréia (2)

dentição infantil (5)

fl

fo

fl $\quad 0,79$

H. polyphyllum Lehm.*

(sete-s an grias)

23.622

limpar o sangue (2)

in

Bromeliaceae

Encholirium spectabile Mart. ex Schult.

f. *

23.889

dor no fígado,

dor nos rins (2)

(macambira-de-boi)

inflamações em geral (1)

0,50

Cactaceae

Cereus albicaulis (Britton \& Rose)

Luetzelb.*

23.447

pedra nos rins (1)

ra $\quad 0,21$

(rabo-de-raposa)

Melocactus zehntneri (Britton \& Rose)

Luetzelb.*

23.448

limpar útero (7)

ca $\quad 0,21$

(cor oa-de-frade; cabeça-de-frade)

Nopalea cochenillifera (L.) Salm-Dyck*

(palma-santa)

23.449

fratura (10)

ca $\quad 0,21$

Pilosocereus gounellei (F .A.C. Weber)

Byles \& G.D. Rowley ${ }^{*}$

23.450

impigem (4)

ca $\quad 0,21$

(xique-xique) 
TABELA 1. Etnoespécies utilizadas como medicinais em 21 comunidades rurais de Oeiras(Piauí - Brasil), no ano de 2007 e 2008. TEPB: número de registro (Herbário Graziela Barroso/UFPI). Indicação. FP- forma de preparo: 1- decocto; 2- infusão; 3- lambedor; 4- garrafada; 5- uso tópico; 6- bochecho; 7- suco; 8- in natura; 9banho; 10- emplastro; 11- sumo; 12- supositório; 13- inalação; 14- molho; PU: parte utilizada: Planta inteira (in); Folhas (fo); Casca (cs); Raiz (ra); Caule (ca); Frutos (fr); Flores (fl); Semente (se); Látex (la); Caule subterrâneobulbo (bu) IR: importância relativa; il: identificado no local. * Espécies nativas.

...continuação

\begin{tabular}{|c|c|c|c|c|}
\hline TAXA & TEPB & Indicação (FP) & PU & IR \\
\hline \multicolumn{5}{|l|}{ Capparaceae } \\
\hline $\begin{array}{l}\text { Cleome spinosa Jacq. } \\
\text { (mussambê) }\end{array}$ & 23.455 & $\begin{array}{c}\text { gripe (1) } \\
\text { tosse (2) } \\
\text { limpar os pulmões (3) }\end{array}$ & $\begin{array}{l}\mathrm{fl} \\
\mathrm{ra} \\
\mathrm{fl}\end{array}$ & 0,36 \\
\hline $\begin{array}{l}\text { Crateva tapia L.* } \\
\text { (trapiá) }\end{array}$ & 23.456 & reumatismo $(5,7)$ & fo & 0,21 \\
\hline \multicolumn{5}{|l|}{ Caricaceae } \\
\hline $\begin{array}{l}\text { Carica papaya L. } \\
\text { (mamão) }\end{array}$ & 23.914 & $\begin{array}{c}\text { prisão de ventre (8) } \\
\text { diabetes (2) } \\
\text { verme (1) } \\
\text { diarréia (1) }\end{array}$ & $\begin{array}{l}\mathrm{fr} \\
\text { fo, fr, } \\
\text { la } \\
\text { fl, fo } \\
\text { fo }\end{array}$ & 0,57 \\
\hline
\end{tabular}

\section{Chenopodiaceae}

Beta vulgaris $\mathrm{L}$. (beterraba)

Chenopodium ambrosioides $\mathrm{L}$. (mastruz)

23.388

il.

Combretaceae

Combretum leprosum Mart.*

(mufumbo)

Terminalia fagifolia Mart.* (chapada)

23.445

anemia (7)
verme,
ferimento $(11)$
inflamações em geral,
gastrite $(7)$
hemorróidas,
fraturas (10)

\section{hemorragias (2)}

afrodisíaco (1) cólicas estomacais (7)

inchaço na barriga (1) dor de estômago (1)

ra 0,21
fo, $\mathrm{fl}$
fo, $\mathrm{fl} \quad 1,14$
fo, $\mathrm{fl}$

\section{Convolvulaceae}

Ipomoea as arifolia (Desr.) Roem.\&

Schult.

(salsa)

23.901

vômito (2)

ra

0,21

I. batatas (L.) Lam.

(batata-doce)

Operculina macrocarpa (L.) Urb.*

(batata-de-purga)

23.900

\section{Cucurbitaceae}

Cayaponia sp. *

(guardião)

Citrullus vulgaris Schrad. ex Eckl. \&

Zeyh.

(melancia) il.

23.910

aumentar a lactação (1) fo $\quad$ fo,21

$\begin{array}{lll}\text { limpar o sangue (7) } & \text { ra } & \\ \text { dentição infantil (1) } & \text { se } & 0,64\end{array}$

gripe (1)

se

mordida de cobra (2)

$\begin{array}{ll}\text { ra } & 0,43\end{array}$

23.594

febre (2)

se $\quad 0,21$ limpar o sangue (1) 
TABELA 1. Etnoespécies utilizadas como medicinais em 21 comunidades rurais de Oeiras(Piauí - Brasil), no ano de 2007 e 2008. TEPB: número de registro (Herbário Graziela Barroso/UFPI). Indicação. FP- forma de preparo: 1- decocto; 2- infusão; 3- lambedor; 4- garrafada; 5- uso tópico; 6- bochecho; 7- suco; 8- in natura; 9banho; 10- emplastro; 11- sumo; 12- supositório; 13- inalação; 14- molho; PU: parte utilizada: Planta inteira (in); Folhas (fo); Casca (cs); Raiz (ra); Caule (ca); Frutos (fr); Flores (fl); Semente (se); Látex (la); Caule subterrâneobulbo (bu) IR: importância relativa; il: identificado no local. * Espécies nativas.

...continuação

\begin{tabular}{|c|c|c|c|c|}
\hline TAXA & TEPB & Indicação (FP) & PU & IR \\
\hline $\begin{array}{l}\text { Cucurbita pepo L. } \\
\text { (abóbora) }\end{array}$ & 23.913 & dor de ouvido (5) & $\mathrm{fl}$ & 0,21 \\
\hline $\begin{array}{l}\text { Lagenaria siceraria (Molina) Standl. } \\
\text { (cabaça) }\end{array}$ & 23.908 & micose (5) & fo & 0,21 \\
\hline $\begin{array}{l}\text { Momordica charantia L.* } \\
\text { (melão-de-são-caetano) }\end{array}$ & 23.906 & $\begin{array}{l}\text { pedra nos rins (1) } \\
\text { hipertensão (1) } \\
\text { impigem (9) } \\
\text { dengue, verme, } \\
\text { reumatismo (2) }\end{array}$ & $\begin{array}{l}\text { fo,in } \\
\text { fo } \\
\text { ra } \\
\text { fo }\end{array}$ & 1,29 \\
\hline $\begin{array}{l}\text { Sechium edule (Jacq.) Sw. } \\
\text { (chuchu) }\end{array}$ & il. & infecção urinária (2) & fo & 0,21 \\
\hline \multicolumn{5}{|l|}{ Cyperaceae } \\
\hline $\begin{array}{l}\text { Cyperus uncinulatus Schrad. ex Nees* } \\
\text { (barba-de-bode) }\end{array}$ & 23.439 & $\begin{array}{l}\text { menstruação } \\
\text { irregular (2) }\end{array}$ & $\mathrm{ra}$ & 0,21 \\
\hline
\end{tabular}

Dilleniaceae

Curatella americana L. *

(sambaiba)

23.859

inflamações em geral (2)

CS inflam ação do útero

e ovários (2) cs

0,93

fraturas (10)

CS

febre, dores nos rins (1)

CS

Dioscoriaceae

Dioscorea alata $\mathrm{L}$.

(cará)

23.860

gastrite, diabetes (8)

fr $\quad 0,43$

Euphorbiaceae

Cnidoscolus quercifolius Pohl*

(cansanção)

23.397

apendicite (7)

verruga (8)

ra $\quad 0,43$

C. loefgrenii (Pax \& K. Hoffm.) Pax \& K.

Hoffm.*

23.393

apendicite (1)

ra

0,21

(cansanção-bravo)

Croton grewioides Baill.*

(canelinha)

23.404

gripe $(1,9)$

fo,fl $\quad 0,21$

C. heliotropiifolius Kunth*

(velame-verdadeiro)

23.403

sinusite (9)

fo

0,21

C. rhamnifolioides Pax \& K. Hoffm. * (velame)

23.407

gripe (1)

fo,fl $\quad 0,21$

C. tenuifolius Pax \& K. Hoffm. ${ }^{*}$

(velaminho; velame-santo)

23.398

dor no corpo,

verme (2)

fo

febre, ameba (1)

0,71

Croton sp. ${ }^{1 *}$

(batata-de-vaqueiro)

23418

febre (2)

ra

Croton sp. ${ }^{2 *}$

(papaconha)

23.601

verme, gripe (2)

fo

0,21

Euphorbia tirucalli $\mathrm{L}$.

(cachorro-pelado)

23.392

ferimento (5)

câncer (7)

ra 0,43

la $\quad 0,43$ 
TABELA 1. Etnoespécies utilizadas como medicinais em 21 comunidades rurais de Oeiras(Piauí - Brasil), no ano de 2007 e 2008. TEPB: número de registro (Herbário Graziela Barroso/UFPI). Indicação. FP- forma de preparo: 1- decocto; 2- infusão; 3- lambedor; 4- garrafada; 5- uso tópico; 6- bochecho; 7- suco; 8- in natura; 9banho; 10- emplastro; 11- sumo; 12- supositório; 13- inalação; 14- molho; PU: parte utilizada: Planta inteira (in); Folhas (fo); Casca (cs); Raiz (ra); Caule (ca); Frutos (fr); Flores (fl); Semente (se); Látex (la); Caule subterrâneobulbo (bu) IR: importância relativa; il: identificado no local. * Espécies nativas.

...continuação

\begin{tabular}{|c|c|c|c|c|}
\hline TAXA & TEPB & Indicação (FP) & PU & IR \\
\hline $\begin{array}{l}\text { Jatropha gossypiifolia L. } \\
\text { (pinhão-roxo) }\end{array}$ & 23.395 & $\begin{array}{c}\text { inflamações em geral (1) } \\
\text { dor nos olhos (2) } \\
\text { dor de cabeça (9) }\end{array}$ & $\begin{array}{l}\text { fo } \\
\text { fo,la } \\
\text { fo }\end{array}$ & 0,64 \\
\hline $\begin{array}{l}\text { J. mollissima (Pohl) Baill.. } \\
\text { (pinhão-bravo) }\end{array}$ & 23.402 & derrame (7) & la & 0,21 \\
\hline $\begin{array}{l}\text { J. ribifolia (Pohl) Baill.* } \\
\text { (pinhão-branco) }\end{array}$ & 23.405 & $\begin{array}{l}\text { inflamações em geral, ferimento (1) } \\
\text { cicatrização de umbigo (5) } \\
\text { gripe, expectorante (9) } \\
\text { garganta inflamada (1) } \\
\text { dor de cabeça (9) }\end{array}$ & $\begin{array}{l}\text { fo } \\
\text { la } \\
\text { fl } \\
\text { fo,la } \\
\text { fo }\end{array}$ & 1,07 \\
\hline $\begin{array}{l}\text { Phyllanthus niruri L.* } \\
\text { (quebra-pedra) }\end{array}$ & 23.400 & $\begin{array}{c}\text { dor no fígado, } \\
\text { pedra nos rins }(2) \\
\text { prisão de ventre }(12)\end{array}$ & $\begin{array}{c}\text { in } \\
\text { se,fo }\end{array}$ & 0,29 \\
\hline $\begin{array}{l}\text { Ricinus communis } \mathrm{L} \text {. } \\
\text { (mamona) }\end{array}$ & 23.408 & $\begin{array}{l}\text { dores em geral (1) } \\
\text { verme (2) } \\
\text { furúnculos (5) } \\
\text { mordida de cobra (7) }\end{array}$ & $\begin{array}{l}\mathrm{fl} \\
\mathrm{fo} f \mathrm{fl} \\
\mathrm{la}\end{array}$ & 0,93 \\
\hline
\end{tabular}

Cypella linearis (Kunth) Baker* (coquinho)

24.032

gripe (4)

in $\quad 0,21$

\section{Krameriaceae}

Krameria tomentosa A.St.-Hil. * (carrapicho-de-bode)
23.750 hemorragias, inflamações em geral,

\section{Lamiaceae}

Hypenia salzmannii (Benth.) Harley* (barriguda)

Hyptis platanifolia Mart. ex Benth. *

(betanca)

H. suaveolens (L.) Poit. *

(bamburral)

23.985

23.459

23.603

Leonotis nepetifolia (L.) R. Br.

(cordão-de-frade; cordão-de-são-

francisco)

23.463

Ocimum americanum L.

(manjericão)

23.458

Plectranthus barbatus Andrews (boldo)

23.919 limpar
o sangue (4)
limpar

ra $\quad 0,50$

Leguminosae

\section{Caesalpinioideae}

Bauhinia acuruana Moric. ${ }^{*}$ (miroró-branco)

23.488

diabetes $(1,2)$

CS

fo $\quad 0,21$ 
TABELA 1. Etnoespécies utilizadas como medicinais em 21 comunidades rurais de Oeiras(Piauí - Brasil), no ano de 2007 e 2008. TEPB: número de registro (Herbário Graziela Barroso/UFPI). Indicação. FP- forma de preparo: 1- decocto; 2- infusão; 3- lambedor; 4- garrafada; 5- uso tópico; 6- bochecho; 7- suco; 8- in natura; 9 banho; 10- emplastro; 11- sumo; 12- supositório; 13- inalação; 14- molho; PU: parte utilizada: Planta inteira (in); Folhas (fo); Casca (cs); Raiz (ra); Caule (ca); Frutos (fr); Flores (fl); Semente (se); Látex (la); Caule subterrâneobulbo (bu) IR: importância relativa; il: identificado no local. * Espécies nativas.

...continuação

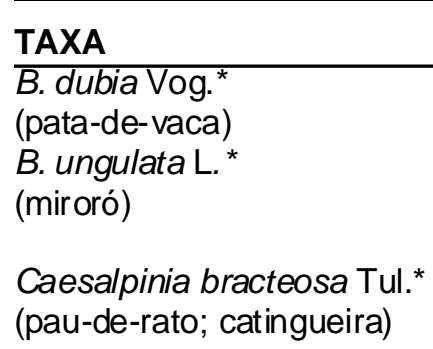

C. ferrea Mart.*

(pau-ferro; jucá)

C. pyramidalis Tul. *

(catingueira)

Dimorphandra gardneriana Tul. *

(fava-d'anta)

Hymenaea courbaril L. *

(jatobá-de-porco)

$H$. eriogyne Benth.*

(jatobá-de-vaqueiro)

Parkinsonia aculeata L. *

(xila)

Senna occidentalis (L.) Link*

(fedegoso)

S. reticulata (Willd.) H.S. Irwin \&

Barneby ${ }^{*}$

(maria-mole)

S. spectabilis (DC.) H.S.Irwin \&

Barneby*

(cana-fliche)

Senna sp. *

(papaconha-mansa)

Tachigali sp.*

(podói; podóia)

Tamarindus indica L. (tamarindo)
23.621

23.497

23.492

23.642

23.491

23.516

23.499

23.508

23.494

23.599

23.544

23.543
PU

PU

IR

colesterol alto (1)

diabetes (1)

diabetes (1)

derrame (1)

prisão de ventre (2)

verme, inflamação da próstata,

flatulência (1)

diarréia (7)

infecção urinária (2)

inflamações em geral,

fratura, bronquite (3)

pancada (10)

anemia, gastrite,

diarréia, gripe, dores nos rins, azia, derrame (4)

inchaço na barriga (2)

diarréia, diabetes (2)

inflamações em geral (4)

gastrite (7)

gripe (3)

dor no corpo (3)

anemia, gripe (3)

cólica intestinal (1)

asma (2)

hipertensão (2)

asma (2)

pano-branco (5)

prisão de ventre (1)

$\begin{array}{cc}\text { PU } & \text { IR } \\ \text { fo } & 0,29 \\ \text { fo,fl } & \\ \text { fo } & 0,43 \\ \text { cs } & \\ \text { fl } & \end{array}$

cs

0,71

fo

cs

CS

CS $\quad 1.86$

cs

fo,fl

CS

CS

0,64

CS

fl

fl $\quad 0,43$

cs $\quad 0,43$

cs $\quad 0,21$

se

fo $\quad 0,43$

se $\quad 0,21$

fl

fo

0,43

erisipela (5)

fo $\quad 0,21$

\section{Mimosoideae}

Mimosa caesalpiniifolia Benth. ${ }^{*}$

(sabiá)

24.029

gripe, verme (1)

ra

0,43

enxaqueca (2)

inflamações em geral (4) prisão de ventre, dores nas costas (1)

cs

CS

CS

prisão de ventre (2)

fo,fl

0,79

fl $\quad 0,21$
M. velloziana Mart. *

(malícia-de-boi)

23.506

derrame (4)
impingem (9)
febre (2)
hipertensão (1)

cs $\quad 0,21$

fo

ra $\quad 0,64$

ra 
TABELA 1. Etnoespécies utilizadas como medicinais em 21 comunidades rurais de Oeiras(Piauí - Brasil), no ano de 2007 e 2008. TEPB: número de registro (Herbário Graziela Barroso/UFPI). Indicação. FP- forma de preparo: 1- decocto; 2- infusão; 3- lambedor; 4- garrafada; 5- uso tópico; 6- bochecho; 7- suco; 8- in natura; 9banho; 10- emplastro; 11- sumo; 12- supositório; 13- inalação; 14- molho; PU: parte utilizada: Planta inteira (in); Folhas (fo); Casca (cs); Raiz (ra); Caule (ca); Frutos (fr); Flores (fl); Semente (se); Látex (la); Caule subterrâneobulbo (bu) IR: importância relativa; il: identificado no local. * Espécies nativas.

...continuação

\begin{tabular}{|c|c|c|c|c|}
\hline TAXA & TEPB & Indicação (FP) & PU & IR \\
\hline Papilionoideae & & & & \\
\hline $\begin{array}{l}\text { Amburana cearensis (Fr.Allem.) } \\
\text { A.C.Sm. }{ }^{*} \text { (imburana-de-cheiro) }\end{array}$ & 23.920 & $\begin{array}{l}\text { bronquite, gripe (3) } \\
\text { mordida de cobra (1) } \\
\text { febre, gripe (9) }\end{array}$ & $\begin{array}{l}\text { cs } \\
\text { se } \\
\text { fo }\end{array}$ & 0,79 \\
\hline $\begin{array}{l}\text { Dioclea violacea Mart. ex Benth.* } \\
\text { (mucunã-de-chapada) } \\
\text { Pterocarpus villosus Mart. ex Benth.* } \\
\text { (pau-de-sangue) }\end{array}$ & 23.644 & inchaço na barriga (2) & la & 0,21 \\
\hline $\begin{array}{l}\text { Swartzia flaemingii var. psilonema } \\
\text { (Harms) R.S.Cowan* } \\
\text { (jacarandá) }\end{array}$ & 23.501 & $\begin{array}{c}\text { reum atismo, pedra } \\
\text { nos rins (4) } \\
\text { inflam ação do útero } \\
\text { e ovários (4) } \\
\text { limpar o sangue (3) } \\
\text { câncer: hipertensão (1) }\end{array}$ & $\begin{array}{l}c s \\
c s, f o \\
c s \\
\text { in, ra }\end{array}$ & 0,86 \\
\hline $\begin{array}{l}\text { Vatairea macrocarpa Ducke* } \\
\text { (am argoso) }\end{array}$ & 23.614 & $\begin{array}{c}\text { cistos ,miomas, colesterol } \\
\text { alto (2) } \\
\text { inflamações em geral (4) }\end{array}$ & ra & 0,86 \\
\hline $\begin{array}{l}\text { Indet. } \\
\text { (catingueira) }\end{array}$ & 23.495 & $\begin{array}{c}\text { dor no corpo (1) } \\
\text { diarréia (1) } \\
\text { azia (1) }\end{array}$ & $\begin{array}{l}\text { fo } \\
\text { cs } \\
\text { fl }\end{array}$ & 0,50 \\
\hline
\end{tabular}

\section{Liliaceae}

Aloe vera (L.) Burm. f.

(babosa)

Allium cepa $\mathrm{L}$.

(cebola)

A. sativum $\mathrm{L}$.

(alho)

A. schoenoprasum L.

(cebolinha) il. hemorróidas (11)

inflam ação do útero

e ovários (1)

il. gripe (3) bu 0,21

il. gripe (2) bu 0,21

23.822

verme, gripe (2)

fo $\quad 0,43$

fo

fo $\quad 0,64$

\section{Loganiaceae}

Strychnos sp. *

(quina)

23.598

Lytraceae

Cuphea laricoides Koehne*

(mãe-catirina)

Malpighiaceae

Bunchosia armeniaca (Cav.) DC.

(cereja)

23.857

dor de estômago (1)

Byrsonima correaefolia A. Juss. *

(murici)

23.857

diarréia (1)

cs

cs $\quad 0,21$

B. variabilis A. Juss. ${ }^{*}$

(murici)

23.972

cólicas estomacais, anemia $(7,8)$

23.953

sangramento de gengiva (2)

in $\quad 0,21$

Diplopterys sp.*

(birro-preto)

23.948

sangramento de gengiva (1)

diarréia (2)

Malpighia emarginata DC. (acerola)

23.959

garganta inflamada (3) cólica menstrual (2)

gripe $(7,8)$ fr $\quad 0,43$

cs $\quad 0,21$

cs $\quad 0,21$

fo

cs $\quad 0,50$

CS

fr $\quad 0,21$ 
TABELA 1. Etnoespécies utilizadas como medicinais em 21 comunidades rurais de Oeiras(Piauí - Brasil), no ano de 2007 e 2008. TEPB: número de registro (Herbário Graziela Barroso/UFPI). Indicação. FP- forma de preparo: 1- decocto; 2- infusão; 3- lambedor; 4- garrafada; 5- uso tópico; 6- bochecho; 7- suco; 8- in natura; 9banho; 10- emplastro; 11- sumo; 12- supositório; 13- inalação; 14- molho; PU: parte utilizada: Planta inteira (in); Folhas (fo); Casca (cs); Raiz (ra); Caule (ca); Frutos (fr); Flores (fl); Semente (se); Látex (la); Caule subterrâneobulbo (bu) IR: importância relativa; il: identificado no local. * Espécies nativas.

...continuação

\begin{tabular}{|c|c|c|c|c|}
\hline TAXA & TEPB & Indicação (FP) & PU & IR \\
\hline \multicolumn{5}{|l|}{ Malvaceae } \\
\hline $\begin{array}{l}\text { Gossypium barbadense L. } \\
\text { (algodão-de-criolo) }\end{array}$ & 23.587 & $\begin{array}{l}\text { queimadura (10) } \\
\text { limpar o sangue (2) } \\
\text { limpar o útero, } \\
\text { útero inflamado (11) } \\
\text { gripe (3) }\end{array}$ & $\begin{array}{l}\text { fo } \\
\text { fo } \\
\text { fo } \\
\text { fo }\end{array}$ & 0,79 \\
\hline $\begin{array}{l}\text { G. hirsutum L. } \\
\text { (algodão) }\end{array}$ & il. & $\begin{array}{l}\text { útero inflamado }(11) \\
\text { afrodisíaco }(1) \\
\text { regulador } \\
\text { menstrua, gripe }(7,11) \\
\text { inflamação da próstata }\end{array}$ & $\begin{array}{l}\text { fo } \\
\text { fo } \\
\text { ra } \\
\text { ra }\end{array}$ & 0,79 \\
\hline $\begin{array}{l}\text { Sida cordifolia L.* } \\
\text { (malva-branca) }\end{array}$ & 23.960 & $\begin{array}{c}\text { infecção urinária (1) } \\
\text { limpar sangue (1) }\end{array}$ & $\begin{array}{l}\text { ra } \\
\text { fo }\end{array}$ & 0,43 \\
\hline \multicolumn{5}{|l|}{ Musaceae } \\
\hline $\begin{array}{l}\text { Musa paradisiaca L. } \\
\text { (banana) }\end{array}$ & il. & $\begin{array}{c}\text { expectorante (1) } \\
\text { asma (7) }\end{array}$ & $\begin{array}{l}f l \\
\text { la }\end{array}$ & 0,29 \\
\hline \multicolumn{5}{|l|}{ Myrtaceae } \\
\hline $\begin{array}{l}\text { Campomanesia velutina (Camb.) O. } \\
\text { Berg* (guabiraba) }^{*}\end{array}$ & 23.922 & $\begin{array}{c}\text { diarréia (2) } \\
\text { cólicas intestinais (1) }\end{array}$ & $\begin{array}{l}\text { fo } \\
\text { cs }\end{array}$ & 0,29 \\
\hline $\begin{array}{l}\text { Eucalyptus globulus Labill. } \\
\text { (eucalipto) }\end{array}$ & il. & $\begin{array}{l}\text { sinusite, congestão } \\
\text { nasal (13) } \\
\text { febre (1) }\end{array}$ & $\begin{array}{l}\text { fo } \\
\text { fo }\end{array}$ & 0,57 \\
\hline $\begin{array}{l}\text { Psidium guajava L.* } \\
\text { (goiaba) }\end{array}$ & 23.970 & diarréia infantil, vômito (2) & fo & 0,29 \\
\hline \multicolumn{5}{|l|}{ Nyctag inaceae } \\
\hline $\begin{array}{l}\text { Boerhavia diffusa L. } \\
\text { (pega-pinto) }\end{array}$ & 23.891 & $\begin{array}{c}\text { inflam ações em geral (1) inflamação } \\
\text { do útero } \\
\text { e ovários (1) } \\
\text { diarréia (2) }\end{array}$ & $\begin{array}{l}\mathrm{ra} \\
\mathrm{ra}, \mathrm{fo} \\
\mathrm{fl}, \mathrm{fo}\end{array}$ & 0,50 \\
\hline
\end{tabular}

Olacaceae

\begin{tabular}{|c|c|c|c|c|}
\hline $\begin{array}{l}\text { Ximenia americana L.* } \\
\text { (ameixa) }\end{array}$ & 23.894 & $\begin{array}{l}\text { inflamação do útero e ovários, } \\
\text { cicatrizante, limpar útero, } \\
\text { limpar o sangue, } \\
\text { aborto (4) } \\
\text { anemia, úlcera, câncer, infecção } \\
\text { urinária, problemas } \\
\text { estom acais (1) } \\
\text { coceira (9) } \\
\text { ferimento, queimadura (5) } \\
\text { diarréia } \\
\text { gastrite (7) } \\
\text { fratura (10) }\end{array}$ & $\begin{array}{l}\text { cs } \\
\text { cs } \\
\text { cs } \\
\text { cs } \\
\text { cs } \\
\text { cs }\end{array}$ & 1,79 \\
\hline \multicolumn{5}{|l|}{ Oxalidaceae } \\
\hline $\begin{array}{l}\text { Averrhoa carambola L. } \\
\text { (carambola) }\end{array}$ & 23.932 & $\begin{array}{l}\text { dor nos rins (1) } \\
\text { diabetes (7) }\end{array}$ & $\begin{array}{l}\text { fo,fr } \\
\text { fr }\end{array}$ & 0,43 \\
\hline
\end{tabular}


TABELA 1. Etnoespécies utilizadas como medicinais em 21 comunidades rurais de Oeiras(Piauí - Brasil), no ano de 2007 e 2008. TEPB: número de registro (Herbário Graziela Barroso/UFPI). Indicação. FP- forma de preparo: 1- decocto; 2- infusão; 3- lambedor; 4- garrafada; 5- uso tópico; 6- bochecho; 7- suco; 8- in natura; 9banho; 10- emplastro; 11- sumo; 12- supositório; 13- inalação; 14- molho; PU: parte utilizada: Planta inteira (in); Folhas (fo); Casca (cs); Raiz (ra); Caule (ca); Frutos (fr); Flores (fl); Semente (se); Látex (la); Caule subterrâneobulbo (bu) IR: importância relativa; il: identificado no local. * Espécies nativas.

...continuação

\begin{tabular}{|c|c|c|c|c|}
\hline TAXA & TEPB & Indicação (FP) & PU & IR \\
\hline \multicolumn{5}{|l|}{ Passifloraceae } \\
\hline $\begin{array}{l}\text { Passiflora cincinnata Mart. } \\
\text { (maracujá-de-vaqueiro) }\end{array}$ & 24.008 & infecção urinária $(2,4)$ & ra & 0,21 \\
\hline \multicolumn{5}{|l|}{ Phytolacaceae } \\
\hline $\begin{array}{l}\text { Petiveria alliacea L. } \\
\text { (tipi; macumba) }\end{array}$ & 23.895 & $\begin{array}{l}\text { inchaço no corpo, } \\
\text { dor nas juntas, } \\
\text { garganta inflamada (1) }\end{array}$ & fo & 0,50 \\
\hline \multicolumn{5}{|l|}{ Piperaceae } \\
\hline $\begin{array}{l}\text { Piper tuberculatum Jacq. } \\
\text { (pimenta-de-macaco) }\end{array}$ & 23.926 & $\begin{array}{l}\text { dor nos rins, reumatismo, } \\
\text { dor no corpo (1) }\end{array}$ & $\mathrm{fr}$ & 0,36 \\
\hline $\begin{array}{l}\text { P. cf. cavalcantei Yunck. } \\
\text { (pimenta-de-macaco) }\end{array}$ & 23.941 & reumatismo (10) & fo & 0,21 \\
\hline \multicolumn{5}{|l|}{ Poaceae } \\
\hline $\begin{array}{l}\text { Cenchrus echinatus L.* } \\
\text { (carrapicho) }\end{array}$ & 23.466 & pedra nos rins (1) & ra & 0,21 \\
\hline $\begin{array}{l}\text { Cymbopogon citratus (DC.) Stapf } \\
\text { (capim-de-cheiro; folha-santa) }\end{array}$ & 23.916 & $\begin{array}{c}\text { calmante, gastrite, hipertensão, } \\
\text { abortivo (2) } \\
\text { dor no corpo (2) }\end{array}$ & $\begin{array}{l}\text { fo } \\
\text { fo }\end{array}$ & 0,86 \\
\hline $\begin{array}{l}\text { Zea mays L. } \\
\text { (milho) }\end{array}$ & il. & $\begin{array}{l}\text { hipertensão }(2) \\
\text { reumatismo }(7) \\
\end{array}$ & $\begin{array}{l}\mathrm{fl} \\
\mathrm{fr}\end{array}$ & 0,43 \\
\hline
\end{tabular}

\section{Punicaceae}

Punica granatum $\mathrm{L}$. (romã)

il. garganta inflamada, rouquidão $(1,7,8)$ fr $\quad 0,29$

\section{Rhamnaceae}

Ziziphus joazeiro Mart. * (juá)

anticaspa (5)

problemas gástricos (2) queimadura

(10)

\section{Rubiaceae}

Coffea arabica L.

(café)

Spermacoce verticillata L. *

(vassourinha)

Tocoyena sellowiana (Cham. \& Schltdl.)

K. Schum.*

(jenipapinho)

Rutaceae

Citrus limonum Risso

(limão-azedo)

C. sinensis osbeck

(laranja)

Ruta graveolens $\mathrm{L}$.

(arruda) il. $\quad$ diabetes (2) se 0,21

23.557 diarréia infantil (2) ra 0,21

23.690 torção, pancada (10) cs 0,29

23.921 gripe (2) fo 0,21

$\begin{array}{cccc}23.968 & \text { febre (2) } & \text { fo } & 0,43 \\ \text { diarréia (2) } & \text { fr } & 0,43\end{array}$

il. $\quad$ aborto (1) fo 0,57

menstruação irregular (1)

fo 
TABELA 1. Etnoespécies utilizadas como medicinais em 21 comunidades rurais de Oeiras(Piauí - Brasil), no ano de 2007 e 2008. TEPB: número de registro (Herbário Graziela Barroso/UFPI). Indicação. FP- forma de preparo: 1- decocto; 2- infusão; 3- lambedor; 4- garrafada; 5- uso tópico; 6- bochecho; 7- suco; 8- in natura; 9banho; 10- emplastro; 11- sumo; 12- supositório; 13- inalação; 14- molho; PU: parte utilizada: Planta inteira (in); Folhas (fo); Casca (cs); Raiz (ra); Caule (ca); Frutos (fr); Flores (fl); Semente (se); Látex (la); Caule subterrâneobulbo (bu) IR: importância relativa; il: identificado no local. * Espécies nativas.

...continuação

\begin{tabular}{|c|c|c|c|c|}
\hline TAXA & TEPB & Indicação (FP) & PU & IR \\
\hline \multicolumn{5}{|l|}{ Sapindaceae } \\
\hline $\begin{array}{l}\text { Magonia pubescens A. St. - Hil.* } \\
\text { (tingui) }\end{array}$ & 23.955 & $\begin{array}{l}\text { dores em geral ( } 2) \\
\text { cic atrizante }(5)\end{array}$ & $\begin{array}{l}c s \\
c s\end{array}$ & 0,57 \\
\hline $\begin{array}{l}\text { Serjania communis Cambess. } \\
\text { (mucunã) }\end{array}$ & 23.935 & $\begin{array}{c}\text { inflam ação do útero e } \\
\text { ovários (4) } \\
\text { prisão de ventre (7) }\end{array}$ & $\begin{array}{l}\mathrm{ca} \\
\mathrm{ca}\end{array}$ & 0,43 \\
\hline $\begin{array}{l}\text { Talisia esculenta Radlk. }{ }^{*} \\
\text { (pitomba) } \\
\text { Scrophulariaceae }\end{array}$ & 23.981 & desidratação (2) & se & 0,23 \\
\hline $\begin{array}{l}\text { Scoparia dulcis } \mathrm{L} \text {. } \\
\text { (vassourinha) }\end{array}$ & 23.980 & $\begin{array}{c}\text { fratura, dor no corpo (4) } \\
\text { gripe (3) } \\
\text { infecção urinária (2) }\end{array}$ & $\begin{array}{l}\text { in } \\
\text { fo } \\
\text { ra }\end{array}$ & 0,71 \\
\hline \multicolumn{5}{|l|}{ Solanaceae } \\
\hline $\begin{array}{l}\text { Capsicum baccatum } \mathrm{L} \text {. } \\
\text { (pimenta-olho-de-olho) } \\
\text { C. frutescens } \mathrm{L} \text {. } \\
\text { (pimenta-malagueta) }\end{array}$ & 23.540 & $\begin{array}{c}\text { torcicolo, } \\
\text { dores musculares (10) } \\
\text { probl. de circulação (14) } \\
\text { hipertensão (1) }\end{array}$ & $\begin{array}{l}\mathrm{fr} \\
\mathrm{fr} \\
\mathrm{fr}\end{array}$ & 0,29 \\
\hline $\begin{array}{l}\text { Lycopersicon esculentum Mill. } \\
\text { (tomate) }\end{array}$ & il. & inflamações (2) & fo & 0,21 \\
\hline $\begin{array}{l}\text { Physalis angulata L.* } \\
\text { (canapu) }\end{array}$ & 23.854 & gastrite (2) & fo & 0,21 \\
\hline Solanum americanum Mill.* & 23.853 & cólicas mestruais (1) & fo & 0,21 \\
\hline $\begin{array}{l}\text { S. crinitum Lam. * } \\
\text { (jiló) }\end{array}$ & 23.546 & puxar espinho (10) & $\mathrm{fr}$ & 0,21 \\
\hline $\begin{array}{l}\text { S. melongena } \mathrm{L} \text {. } \\
\text { (beringela) }\end{array}$ & 24.005 & colesterol alto (7) & $\mathrm{fr}$ & 0,21 \\
\hline $\begin{array}{l}\text { S. palinacanthum Dunal* } \\
\text { (melancia-do-mato; jiló) }\end{array}$ & 23.545 & $\begin{array}{l}\text { dor nos rins }(7) \\
\text { tuberculose }(4)\end{array}$ & $\begin{array}{l}\mathrm{fr} \\
\mathrm{ra}\end{array}$ & 0,43 \\
\hline \multicolumn{5}{|l|}{ Sterculiaceae } \\
\hline $\begin{array}{l}\text { Helicteres muscosa Mart. } \\
\text { (moleque-duro) }\end{array}$ & 23.949 & criança andar (1) & fo & 0,21 \\
\hline \multicolumn{5}{|l|}{ Tiliaceae } \\
\hline $\begin{array}{l}\text { Luehea candicans Mart.* } \\
\text { (açoita-cavalo-verdadeiro, } \\
\text { (açoita-cavalo-branco) }\end{array}$ & 23.938 & $\begin{array}{c}\text { gripe (1) } \\
\text { inflamação do útero } \\
\text { e ovários }(4) \\
\text { dor no corpo }(2)\end{array}$ & $\begin{array}{l}\mathrm{cs} \\
\mathrm{cs} \\
\mathrm{cs}\end{array}$ & 0,64 \\
\hline
\end{tabular}

\section{Turneraceae}

Turnera coerulea Sessé \& Moc. ex DC.* (tira-estrepe)

T. subulata $\mathrm{Sm}$.*

(ranca-es trepe)

T. ulmifolia L.*

(chanana)

Velloziaceae

\section{Barbacenia stenophylla Goethart \&}

Henrard*

(macambira-de-morro)
24.023 inflamações em geral (1) in 0,21

inflamação do útero e
ovários (1) $\quad$ ra $\quad 0,21$

23.982 hipertensão (1) ra 0,21 
TABELA 1. Etnoespécies utilizadas como medicinais em 21 comunidades rurais de Oeiras(Piauí - Brasil), no ano de 2007 e 2008. TEPB: número de registro (Herbário Graziela Barroso/UFPI). Indicação. FP- forma de preparo: 1- decocto; 2- infusão; 3- lambedor; 4- garrafada; 5- uso tópico; 6- bochecho; 7- suco; 8- in natura; 9banho; 10- emplastro; 11- sumo; 12- supositório; 13- inalação; 14- molho; PU: parte utilizada: Planta inteira (in); Folhas (fo); Casca (cs); Raiz (ra); Caule (ca); Frutos (fr); Flores (fl); Semente (se); Látex (la); Caule subterrâneobulbo (bu) IR: importância relativa; il: identificado no local. * Espécies nativas.

...continuação

\begin{tabular}{|c|c|c|c|c|}
\hline TAXA & TEPB & Indicação (FP) & PU & IR \\
\hline \multicolumn{5}{|l|}{ Verbenaceae } \\
\hline $\begin{array}{l}\text { Lippia alba (Mill.) N.E.Br. } \\
\text { (erva-cidreira) }\end{array}$ & 23.931 & $\begin{array}{c}\text { gripe, diarréia (1) } \\
\text { hipertensão,calmante (1) } \\
\text { enxaqueca, convulsão, diarréia (1) } \\
\text { má digestão (1) }\end{array}$ & $\begin{array}{l}\text { fo } \\
\text { fl } \\
\text { fo }\end{array}$ & 1,14 \\
\hline $\begin{array}{l}\text { Lippia sp. }{ }^{1 *} \\
\text { (alecrim) }\end{array}$ & 23.605 & gripe $(1,9)$ & fo & 0,21 \\
\hline $\begin{array}{l}\text { Lippia sp. } \\
\text { (alecrim -de-passos; alecrim-de-bom - } \\
\text { jesus) }\end{array}$ & 24.003 & sinusite (9) & fo, fl & 0,21 \\
\hline $\begin{array}{l}\text { Indet. } \\
\text { (hortelão) }\end{array}$ & 23.946 & gripe $(1,3,13)$ & fo, fl & 0,21 \\
\hline \multicolumn{5}{|l|}{ Violaceae } \\
\hline $\begin{array}{l}\text { Hybanthus oppositifolius (L.) Taub.* } \\
\text { (papaconha) }\end{array}$ & 23.611 & dentição infantil (1) & $\mathrm{fl}$ & 0,21 \\
\hline \multicolumn{5}{|l|}{ Vochysiaceae } \\
\hline $\begin{array}{l}\text { Callistene fasciculata Mart. } \\
\text { (capitão-de-campo) }\end{array}$ & 23.986 & doenças de criança (1) & fo & 0,21 \\
\hline $\begin{array}{l}\text { Qualea grandiflora Mart.* } \\
\text { (pau-de-terra-da-folha-larga) }\end{array}$ & 23.936 & coceira (9) & ra & 0,21 \\
\hline \multicolumn{5}{|l|}{ Zingiberaceae } \\
\hline $\begin{array}{l}\text { Curcuma longa L. } \\
\text { (açafroa) }\end{array}$ & il. & rouquidão (1) & bu & 0,21 \\
\hline $\begin{array}{l}\text { Zingiber officinale Roscoe } \\
\text { (gengibre) }\end{array}$ & il. & $\begin{array}{c}\text { garganta, } \\
\text { amigdalite (1) } \\
\text { gripe, sinusite (2) } \\
\text { asma (1) }\end{array}$ & $\begin{array}{l}\text { bu } \\
\text { bu } \\
\text { bu }\end{array}$ & 0,64 \\
\hline
\end{tabular}

A maioria das espécies utilizadas como medicinais pertencem a vegetação nativa $(65,86 \%)$. Este dado corrobora com os apresentados em pesquisas desenvolvidas no Piauí por Abreu (2000) no Quilombo Mimbó em Amarante, por Franco (2005) no Quilombo Olhos D'água dos Pires em Esperantina e por Vieira (2008) no Quilombo dos Macacos, em São Miguel do Tapuio.

As espécies cultivadas empregadas na medicina (32,33\%) são encontradas principalmente nos quintais, nas proximidades das residências e nos locais de cultivo, sendo frequentes Spondias purpurea (seriguela), Psidium guajava (goiaba) e Malpighia emarginata (acerola), como também referido por Florentino et al. (2007), em pesquisa com quintais no semiárido pernambucano. Do total, $1,79 \%$ das espécies não foram identificadas.

Dentre as espécies nativas, a aroeira (Myracrodruon urundeuva) está incluída na lista oficial de espécies ameaçadas de extinção, na categoria vulnerável do IBAMA (www.ibama.gov.br) e foi também referida como medicinal por Silva (2003) em pesquisa com os índios Fulni-ô em Pernambuco e no Piauí, por Chaves et al. (2006) em Cocal, por Santos et al. (2007) em Monsenhor Gil, por Franco et al. (2007) no Quilombo Olho D'água dos Pires, em Esperantina/PI e por Vieira et al. (2008) no Quilombo dos Macacos, em São Miguel do Tapuio.

Em consonância com a pesquisa de campo, explicitam-se os diferentes usos e indicações terapêuticas, como sintoma de determinada doença (dor de cabeça, diarréia, febre, cólica intestinal, inflamações, dentre outros) bem como a própria doença é alvo da indicação (gripe, diabetes, gastrite, hipertensão, apendicite, etc.).

As partesutilizadas foram a folha $(31,5 \%)$, casca $(16,3 \%)$, raiz $(14,8 \%)$, flor $(10,9 \%)$, fruto $(7 \%)$, semente $(6,5 \%)$, planta inteira $(4,6 \%)$, látex $(3,9 \%)$ e caule: aéreo $(3,1 \%)$ e subterrâneo (1,4\%). Nesse sentido, ressalta-se quea folhaé a parte do vegetal mais utilizada na medicina caseira local, representando $31,5 \%$ dos casos, para o tratamento de todas as doenças citadas, embora 
não esteja disponível o ano todo, em função da caducifólia na época da seca, os moradores a desidratam e armazenam. As cascas perfizeram 16,3\% das citações, sendo comumente referido que a coleta deve ser feita antes do nascer do sol e, além disso, deve-se colocá-las em local sombreado, para que não perca as propriedades terapêuticas. Resultado análogo para as folhas observou-se nos trabalhos de Amorozo (2002) em Tanquinho/BA, Chaves (2005) em Cocal/ PI; Fuck et al. (2005) em Bandeirantes/PR e Franco \& Barros (2006) no Quilombo Olho D'água dos Pires, Esperantina/PI.

Não obstante a relevância da indicação do látex de Euphorbia tirucalli para o tratamento de câncer, o mesmo também foi citado como tóxico, se empregado em quantidade superior a duas gotas. Cenário similar foi descrito no Piauí por Vieira (2008), no Quilombo dos Macacos, São Miguel do Tapuio e por Oliveira et al. (2009), em Oeiras. Segundo Lorenzi \& Matos (2002), o látex é utilizado em algumas regiões do país para remover melanomas em pequenas dosagens, não havendo, entretanto, nenhuma evidência científica de possível atividade anticancerígena. Contudo, estudos do herbalista Dr. Acorsi da ESALQ/USP (Apud Lorenzi \& Matos, 2002), revelaram que o uso interno da planta possui ação antitumoral em doses extremamente baixas.

Ademais, evidencia-se que os entrevistados expuseram às propriedades terapêuticas da arruda (Ruta graveolens), no combate a dor de dente, regulador menstrual e abortiva; da mamona (Ricinus communis), empregada contra a prisão de ventre, dores em geral, vermífugo, antitumoral e mordida de cobra; e o melão-de-são-caetano (Momordica charantia) utilizado em caso de hipertensão, impigem, dengue, pedra nos rins, reumatismo e vermífugo. Ritter et al. (2002) as reconheceu em pesquisa com plantas utilizadas como medicinais no município de Ipê, RS, como tóxicas. Desse modo, durante a pesquisa, houve alguns relatos de intoxicação pelo uso dessas plantas, que, segundo os informantes, se deu em função do uso inadequado, através do emprego de dosagem acima da recomendada.

As espécies Myracrodruon urundeuva, Ruta graveolens, Spondias tuberosae Ximenia americana tiveram o uso desaconselhado durante a gravidez, devido às propriedades abortivas. Igualmente, Cymbopogon citratus e Plectranthus barbatus foram contra-indicados durante a gestação. Este panorama foi análogo ao apresentado por Vendruscolo et al. (2005) em estudo realizado na comunidade do Bairro Ponta Grossa, Porto Alegre/RS.

Em conformidade com a Figura 1, as formas de preparo mais utilizadas foram a decocção (32,2\% dos casos), infusão $(23,8 \%)$, garrafada $(9,9 \%)$, suco $(7,5 \%)$, lambedor $(6,5 \%)$ e uso tópico $(4,9 \%)$. Medeiros et al. (2003) em pesquisa em Santa Teresa/ ES e Pinto et al. (2006) em comunidades rurais de Itacaré/BA, também verificaram a decocção como a forma de preparo mais frequente. Segundo os informantes, a infusão assegura a eficácia do medicamento para algumas plantas ou parte destas, a exemplo de Citrus limon, Cymbopogon citratus e Psidium guajava. Estudos químicos e farmacológicos, realizados por Vendruscolo et al. (2005), revelaram que o óleo presente nas folhas destas plantas é volátil.

Além do uso em separado, verificou-se que é prática bastante comum o uso em associação de várias espécies para a produção de lambedores e garrafadas, no combate a um sintoma ou doença em

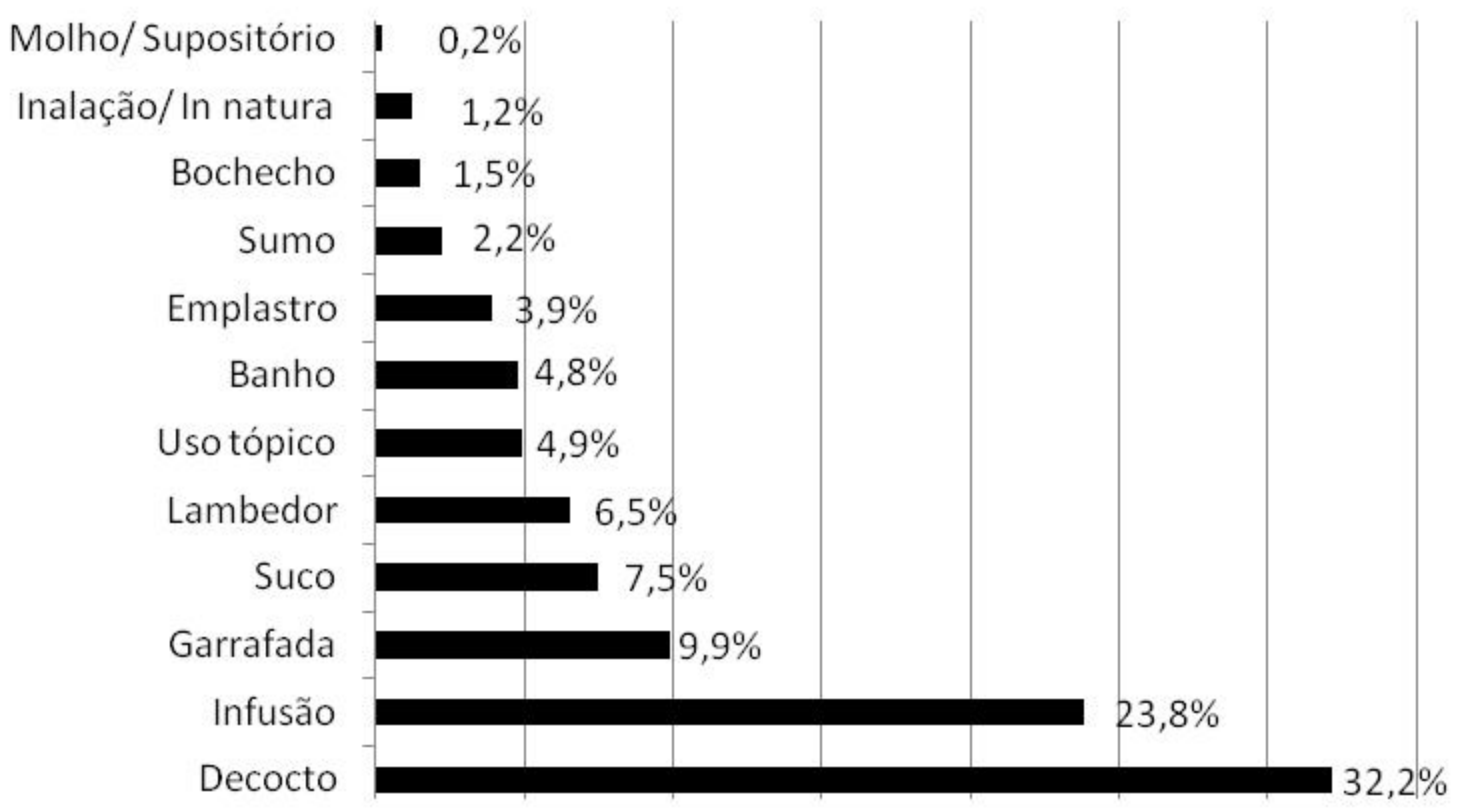

FIGURA 1. Formas de preparo das espécies usadas como medicinais no município de Oeiras, Piauí, Brasil. 
particular, fato também referido por Pinto et al. (2006) em Itacaré/BA, Franco \& Barros (2006) em Esperantinal PI e Vieira (2008) em São Miguel do Tapuio/PI.

Nas comunidades pesquisadas o uso de plantas na medicina para o tratamento de doenças ou manutenção da saúde emerge como primeira opção, e muitas vezes única, especialmente pela dificuldade deslocamento até a sede do município, onde são oferecidos serviços da medicina tradicional.

O conhecimento das propriedades terapêuticas da vegetação local foi adquirido através dos antepassados, por transmissão oral, constituindose em importante aspecto da cultura local. No entanto, 0 repasse e a permanência desse conhecimento encontram-se ameaçados devido à influência de fatores externos aos grupos e a maior exposição à sociedade envolvente, especialmente derivado das pressões econômicas, acesso aos serviços da medicina moderna e à emigração das pessoas para centros urbanos (Amorozo \& Gely, 1988; Nolan \& Robbins, 1999; Lima et al., 2000; Amorozo, 2002; Pinto et al., 2006).

Identificou-se por meio da pesquisa o registro da Acanthospermum hispidum para o tratamento de doenças respiratórias; Lippia alba, Plectranthus barbatus e Psidium guajava para problemas no aparelho digestório; Averrhoa carambola para o tratamento de problemas renais e Anacardium ocidentale como antiinflamatória e cicatrizante. Dados semelhantes são apresentados por Silva \& Andrade (2005) no litoral e zona da mata de Pernambuco e por Abreu (2000) na comunidade Mimbó, município de Esperantina/PI, os quais constataram uma frequência significativa de indicações para tratamentos de problemas do aparelho reprodutor feminino, especialmente na forma de garrafada.

Emilia sonchifolia, Orbignya phalerata e Tabebuia impetiginosa, foram também referidas para o tratamento de problemas dermatológicos por Macêdo \& Ferreira (2004) em estudo nas comunidades da Bacia do Alto do Paraguai/MT. Lippia alba foi indicada para o tratamento de diarréia e Chenopodium ambrosioides como vermífugo. Esses dados corroboram com os apresentados por Begossi et al. (1993) na comunidade pesqueira da llha dos Búzios, no litoral paulista e por Pinto et al.(2006). Do mesmo modo da presente pesquisa, Bowdichia virgilioides, Magonia pubescens e Caryocar coriaceum tiveram indicações terapêuticas em pesquisa realizada por Jenrich (1989) em Oeiras/PI.

Acanthospermum hispidum, Amburana cearensis, Anacardium occidentale, Annona squamosa, Boerhavia diffusa, Caesalpinia ferrea, Carica papaya, Chenopodium ambrosioides, Cleome spinosa, Croton rhamnifolius, Cymbopogon citratus, Heliotropium indicum, Hymenaea courbaril, Lippia alba, Malpighia emarginata, Mangifera indica,
Melocactus zehntneri, Momordica charantia, Myracrodruon urundeuva, Psidium guajava, Senna spectabilis, Spondias purpurea, Talisia esculenta e Ziziphus joazeiro, foram igualmente referenciados como medicinais em comunidades rurais da caatinga pernambucana, como mostrado por Albuquerque \& Andrade (2002).

As espécies de plantas que particularmente apresentaram grande versatilidade quanto aos usos, verificado através do cálculo de Importância Relativa foram o pau-ferro (Caesalpinia ferrea) (IR=1,86), a ameixa (Ximenia americana) $(1,79)$ e a aroeira (Myracrodruon urundeuva) (1,21), espécies igualmente citadas com IR superior a 1,0 por Vieira (2008). O número de usos terapêuticos relacionado a estas espécies está entre os maiores. $C$. ferrea foi indicada para o tratamento da bronquite, gastrite, anemia, inflamações em geral, diarréia, gripe, dores nos rins, azia, derrame, infecção urinária e, ainda, como cicatrizante. Dentre as espécies que obtiveram IR inferior a 0,25, estão Mimosa caesalpiniifolia, Parkia platycephala, Dioclea violacea e Pterocarpus villosus indicadas no tratamento de derrame, epilepsia, asma e inchaço na barriga, respectivamente.

Consoante à Tabela 2 , foi verificado que na categoria medicinal o maior consenso de uso entre os informantes nas comunidades rurais pesquisadas foi gravidez, parto, puerpério ( $F C I 0,55$ ), seguida por doenças do sangue e órgãos homatopoiéticos $(0,47)$, doenças do sangue e órgãos hematopoiéticos $(0,47)$, doenças do sistema ósteo-muscular e tecido conjuntivo $(0,45)$ e neoplasias e doenças virais $(0,43)$, confirmando que as espécies empregadas dentro dessas categorias são relevantes para a cultura local (Tabela 2). Para o transtorno do sistema sensorial (visão) não houve consenso entre os informantes, resultado análogo foi referido por Silva (2003) com os Índios Fulni-ô/PE.

Através da pesquisa foi constatado o significativo montante de espécies (166) mencionadas como úteis para o tratamento de sinais e sintomas de doenças, distribuídas em 59 famílias botânicas. Os produtos obtidos dos recursos disponíveis na região, tanto nativos como cultivados, são aproveitados na terapia para cura e manutenção da saúde, representando prática bastante disseminada na cultura local.

Reconhecidamente, o estudo do emprego popular de plantas medicinais é ferramenta importante na descoberta de novos fármacos, logo que o uso e permanência de determinadas plantas dentro de uma comunidade sugere que ela possua real eficácia, como tem mostrado estudos farmacológicos de etnoespécies por Costa (2006), em pesquisa com o Plectranthus barbatus e por Rodrigues et al. (2006), em estudo de plantas medicinais a partir da etnofarmacologia. 
TABELA 2. Fator de Consenso dos Informantes sobre as plantas utilizadas como medicinais no município de Oeiras, Piauí, Brasil. $\mathrm{FCl}$ = fator de consenso dos informantes; $\mathrm{DMC}=$ doença mais citada dentro da categoria.

\begin{tabular}{lcccc}
\hline Categorias & FCl & $\begin{array}{c}\text { No- de } \\
\text { espécies }\end{array}$ & $\begin{array}{c}\text { citações } \\
\text { reportadas }\end{array}$ & DMC \\
\hline Gravidez, parto, puerpério & 0,55 & 6 & 12 & limpar útero \\
Doenças do sangue e órgãos homatopoiéticos & 0,47 & 18 & 33 & limpar sangue \\
$\begin{array}{l}\text { Doenças do sistema ósteo-muscular e tecido } \\
\text { conjuntivo }\end{array}$ & 0,45 & 24 & 43 & reumatismo \\
Neoplasias e doenças virais & 0,43 & 5 & 8 & câncer \\
Transtornos do sistema nervoso & 0,36 & 15 & 23 & dor de cabeça \\
Impotência sexual & 0,33 & 3 & 4 & afrodisíaco \\
Doenças de pele e do tecido subcutâneo & 0,32 & 27 & 39 & coceira \\
Transtornos do sistema digestório & 0,31 & 26 & 37 & gastrite \\
Doenças endócrinas, nutricionais e metabólicas & 0,30 & 15 & 21 & diabetes \\
Transtornos do sistema cardiovascular & 0,23 & 15 & 20 & hipertensão \\
Inflamações e dores em geral & 0,22 & 29 & 37 & dor no corpo \\
Sintomas e sinais gerais & 0,16 & 39 & 46 & febre \\
Transtorno do sistema sensorial (visão) & 0,00 & 1 & 1 & dor nos olhos \\
\hline
\end{tabular}

Foi notado que há a utilização de todas as partes das plantas, sobressaindo-se o uso das folhas na medicina, apesar da caducifolia. Os espécimes foram citados, além da categoria medicinal, em mais doze categorias de uso (alimentação, artesanal, forrageira, higiene/limpeza, madeireira, melífera, tóxica, ornamental, produção de energia, utensílios, mágico-religiosa e veterinária), demonstrando a amplitude do conhecimento e versatilidade de usos acerca da vegetação.

\section{AGRADECIMENTO}

Aos informantes das comunidades rurais do município de Oeiras, pelo repasse das informações. Aos taxonomistas pela disponibilidade em confirmar e/ou identificar o material botânico. As professoras Maria Bernadete Costa e Silva e Maria do Socorro Lira Monteiro pela disponibilidade e valiosas sugestões. E, de forma especial, ao Luciano Santana, Fábio José Vieira e Geraleno Barros, que espontaneamente envolveram-se neste trabalho.

\section{REFERÊNCIA}

ABREU, J.R. Diversidade de recursos vegetais do cerrado utilizadas pelos quilombolas Mimbó, Amarante. 2000. 69p. Dissertação (Mestrado em Biologia Vegetal) - Universidade Federal de Pernambuco, Recife.

ALBUQUERQUE, U.P.; ANDRADE, L.H.C. Uso dos recursos vegetais da caatinga: o caso do agreste do Estado de Pernambuco. Interciência, v.27, n.7, p.336-45, 2002.

ALBUQUERQUE, U.P.; LUCENA, R.F.P.; ALENCAR, N.L. Métodos e técnicas para coleta de dados etnobotânicos. In: ALBUQUERQUE, U.P.; LUCENA, R.F.P.; CUNHA, L. V.F.C. (Orgs.). Métodos e técnicas na pesquisa etnobotânica. 2.ed. Recife: Comunigraf. 2008, p.41-72. AMOROSO, M.C.; GELY, A. Uso de plantas medicinais por caboclos do baixo Amazonas, Barbacena, Pará, Brasil. Boletim do Museu Paraense Emílio Goeldi, v.4, n.1, p.47-131, 1988.

AMOROZO, M.C.M. Uso e diversidade de plantas medicinais em Santo Antônio do Leverger, MT, Brasil. Acta Botanica Brasilica, v.16, n.2, p.189-203, 2002. AZEVEDO, S.K.S.; SILVA, I.N. Plantas medicinais e de uso religioso comercializadas em mercados e feiras 
livres no Rio de Janeiro, RJ, Brasil. Acta Botanica Brasilica, v.20, n.3, p.185-94, 2006.

BEGOSSI, A.; LEITÃO-FILHO, H.F.; RICHERSON, P.J. Plant uses in a Brazilian fishing community - Búzios Island. Journal of Ethnobiology, v.13, n.2, p.233-56, 1993. BENNETT, B.C.; PRANCE, G.T. Introduced plants in the indigenous pharmacopeia of Northern South America. Economy Botany, v.54, n.1, p.90-102, 2000.

BERG, M.E.; SILVA, M.H.L. Contribuição ao conhecimento da flora medicinal do Piauí. REUNIÃO NORDESTINA DE BOTÂNICA, 8., 1985, Recife. Anais... Recife: Sociedade Botânica do Brasil, 1985. p.151-64.

BORBA, A.M.; MACÊDO, M. Plantas medicinais usadas para a saúde bucal pela comunidade do bairro Santa Cruz, Chapada dos Guimarães. Acta Botanica Brasilica, v.20, n.20, p.771-82, 2006.

CASTELLUCCI, S. et al. Plantas medicinais relatadas pela comunidade residente na Estação Ecológica de Jataí, Município de Luis Antonio/SP: uma abordagem etnobotânica. Revista Brasileira de Plantas Medicinais, v.3, n.1, p.51-60, 2000.

CEPRO - Fundação Centro de Pesquisas. Perfil dos Municípios. Teresina: Fundação CEPRO, 1992. 420p.

CEPRO - Fundação Centro de Pesquisas. Perfil dos Municípios. Teresina: Fundação CEPRO, 2000. 420p. CHAVES, E.M.F. Florística e potencialidades econômicas da vegetação de carrasco no município de Cocal. 2005. 112p. Dissertação (Mestrado em Desenvolvimento e Meio Ambiente) - Universidade Federal do Piauí, Teresina.

CHAVES, E.M.F.; BARROS, R.F.M.; SÉRVIO JÚNIOR, E.M. Plantas do carrasco da Ibiapaba. Terezina: Fundação de Amparo à Pesquisa do Estado do Piauí, 2006. Disponível em:<http://www.fapepi.pi.gov.br/carrasco>. Acesso em: 14 out. 2008.

COSTA, M.C.C.D. Uso popular e ações farmacológicas de Plectranthus barbatus Andr. (Lamiaceae): revisão dos trabalhos publicados de 1970 a 2003. Revista Brasileira de Plantas Medicinais, v.8, n.2, p.81-8, 2006.

COUTINHO, D.F. Estudo etnobotânico de plantas medicinais utilizadas em comunidades indígenas no estado do Maranhão. Visão Acadêmica, v.3, n.1, p.7-12, 2002.

CRONQUIST, A. An integrated of classification of flowering plants. New York: Columbia Universaty Press, 1981. 1262p.

FLORENTINO, A.T.N.; ARAÚJO, E.L.; ALBUQUERQUE, U.P. Contribuição de quintais agroflorestais na conservação de plantas da Caatinga, Município de Caruaru, PE, Brasil. Acta Botanica Brasilica, v.21, n.1, p37-47, 2007.

FRANCO, E. A.P.A. A etnobotânica e o desenvolvimento sustentável no Quilombo Olho D'água dos Pires, Esperantina. 2005. p.134. Dissertação (Mestrado em Desenvolvimento e Meio Ambiente) - Universidade Federal do Piauí, Teresina.

FRANCO, E.A.P.A.; BARROS, R.F.M. Uso e diversidade de plantas medicinais no Quilombo Olho D'água dos Pires, Esperantina, Piauí. Revista Brasileira de Plantas Medicinais, v.8, n.3, p.78-88, 2006.

FRANCO, E.A.P.A.; BARROS, R.F.M.;ARAUJO, J.L.L. Uso e diversidade de plantas do cerrado utilizadas pelos quilombolas de Olho D’água dos Pires, Esperantina,
Piauí. In: LOPES, W.G.R. et al. (Orgs.). Cerrado piauiense: uma visão multidisciplinar. Teresina: EDUFPI, 2007. p. 247-70. (Série Desenvolvimento e Meio Ambiente). FRANCO, I.J.; FONTANA, V.L. Ervas e plantas: a medicina dos simples. Erexim: Edelbra, 2002. 246p.

FUCK, S.B. et al. Plantas medicinais utilizadas na medicina popular por moradores da zona urbana de Bandeirantes, Paraná. Semina, v.26, n.3, p.291-6, 2005. GONÇALVES, M.I.A.; MARTINS, T.D.O. Plantas medicinais usadas pela população do município de Santo Antônio do Leverger, Mato Grosso. Revista Brasileira de Farmácia, v.79, n.3, p.10-25, 1998.

IBAMA. Lista oficial de flora ameaçada de extinção. Instrução Normativa n.06. Disponível em: <http:// www.ibama.gov.br/flora/extinção.htm>. Acesso em: 30 set. 2008.

INPI. International Plant Names Index. Disponível em http://www.ipni.org. Acesso em: 22 set. 2008.

JENRICH, H. Vegetação arbórea e arbustiva nos altiplanos das chapadas do Piauí Central: características, ocorrência, empregos. Teresina: DNOCS; Eschborn: BMZ/GTZ, 1989. 90p.

JUDD, W.S. et al. Plant sistematics: a phylogenic approach. Sunderland: Sinauer Associates, 1999. 464p.

LIMA, R.X.; SILVA, S.M.; SILVA, Y.S.K.L. Etnobiologia de comunidades continentais da Área de Proteção Ambiental de Guaraqueçaba, Paraná. Etnoecológica, v.4, p.33-54, 2000.

LORENZI, H.; MATOS, F.J.A. Plantas medicinais do Brasil: nativas e exóticas. Nova Odessa, SP: Instituto Plantarum, 2002. 336p.

MACEDO, M.; FERREIRA, A.R. Plantas medicinais usadas para tratamentos dermatológicos, em comunidades da Bacia do Alto Paraguai, Mato Grosso. Revista Brasileira de Farmacognosia, v.14, supl.1, p.404, 2004.

MEDEIROS, M.F.T.; FONSECA, V.S.; ANDREATA, R.H.P. Plantas medicinais e seus usos pelos sitiantes da Reserva Rio das Pedras, Mangaratiba, RJ. Acta Botanica Brasilica, v.18, n.2, p.391-9, 2003.

MILLIKEN, W.; ALBERT, B. The use of medicinal plants by the Yanomamy Indians of Brazil. Economic Botany, v.50, n.1, p.10-25, 1996.

MOBOT. Missouri Garden W3 tropicos. Disponível em: <http:// www.mobot.mobot.org>. Acesso em: 05 nov. 2008. MORI, S.A. et al. Manual de manejo do herbário fanerogâmico. 24.ed. Bahia: Centro de Pesquisa do Cacau, 1989. 104p.

NOLAN, J.M.; ROBBINS, M.C. Cultural conservation of medicinal plant use in the Ozarks. Human Organization, v. 58, p.67-72, 1999.

NUNES, G.P. et al. Plantas medicinais comercializadas por raizeiros no centro de Campo Grande, Mato Grosso do Sul. Revista Brasileira de Farmacognosia, v.13, n.2, p.83-92, 2003.

OLIVEIRA, F.C.S. Conhecimento botanico tradicional em comunidades rurais do semiárido piauiense. 2008. 134p. Dissertação (Mestrado em Desenvolvimento e Meio Ambiente) - Universidade Federal do Piauí, Teresina.

OLIVEIRA, F.C.S.; VIEIRA, F.J.; SANTOS, L.G. Produtos florestais forrageiros, nocivos e de uso veterinário, utilizados por camponeses, município de Oeiras, Piauí. In:

Rev. Bras. PI. Med., Botucatu, v.12, n.3, p.282-301, 2010. 
LOPES, W.G.R. et al. (Orgs.). Sustentabilidade do semiárido. v.3., 2009. p.395-416.

OMS - Organização Mundial de Saúde. Classificação estatística internacional de doenças e problemas relacionados à saúde. 10.ed. São Paulo: Editora da Universidade de São Paulo, 2000. 1191p.

PEREIRA, R.C.; OLIVEIRA, M.T.R; LEMOS, G.C.S. Plantas utilizadas como medicinais no município de Campos de Goytacazes, Rio de Janeiro. Revista Brasileira de Farmacognosia, v.14, supl. 1, p.37-40, 2004.

PINTO, E.P.P.; AMOROZO, M.C.M; FURLAN, A. Conhecimento popular sobre plantas Medicinais em comunidades rurais de mata atlântica - Itacaré, BA. Acta Botanica Brasilica, v.20, n.4, p.751-62, 2006.

RÊGO, T.J.A.S. Levantamento de plantas medicinais na baixada maranhense. Acta Amazônica, v.18, n.2, p.7588, 1998.

RITTER, M.R. et al. Plantas usadas como medicinais no município de Ipê, rio Grande do Sul. Revista Brasileira de Farmacognosia, v.12, p.51-62, 2002.

RODRIGUES, E. et al. A investigação de plantas medicinais a partir da etnofarmacologia In: ALBUQUERQUE, U.P. et al. (Orgs.). Atualidades em etnobiologia e etnoecologia. 2.ed. Recife: NUPEEA Núcleo de Publicações em Ecologia e Etnobotânica Aplicada, 2006. p.107-20.

RODRIGUES, V.E.G.; CARVALHO, D.A. Levantamento etnobotânico de plantas medicinais no domínio do cerrado na região do Alto Rio grande, Minas Gerais. Ciência Agrotécnica, v.25, n.1, p.102-23, 2001.

SANTOS, L.G.P.; BARROS, R.F.M.; ARAÚJO, J.L.L. Diversidade de plantas medicinais e forrageiras do cerrado de Monsenhor Gil, Piauí. In: LOPES, W.G.R. et al. (Orgs.). Cerrado piauiense: uma visão multidisciplinar. Teresina: EDUFPI, (Série Desenvolvimento e Meio Ambiente). 2007. p.299-318.

SILVA, A.J.R.;ANDRADE, L.H.C. Etnobotânica nordestina: estudo comparativo da relação entre comunidades e vegetação na Zona do litoral - Mata do Estado de Pernambuco. Acta Botanica Brasilica, v.19, n.1, p.8597, 2005.

SILVA, V.A. Etnobotânica dos índios Fulni-ô, Pernambuco. 2003. 132 p. Tese (Doutorado em Biologia Vegetal) - Universidade Federal de Pernambuco, Recife. SOUSA, C.D.; FELFILI, J.M. Uso de plantas medicinais na região de Alto Paraíso de Goiás. Acta Botanica Brasilica, v.20, n.1, p.135-42, 2006.

TROTTER, R.; LOGAN, M. Informant consensus: a new approach for identifying potentially effective medicinal plants. In: ETKIN N. L. Indigenous medicine and diet: biobehavioural approaches. Nova York: Redgrave, 1986. p.91-111.

VENDRUSCOLO, G.S.; RATES, S.M.K.; MENTZ, L.A. Dados químicos e farmacológicos sobre as plantas utilizadas como medicinais pela comunidade do bairro Ponta Grossa, Porto Alegre. Revista Brasileira de Farmacognosia, v.15, p.361-72, 2005.

VIEIRA, F.J. et al. Quilombola of Macacos Community, São Miguel do Tapuio city, Piauí state: history, use and conservation of plant resources. Functional Ecosystems and Communities, v.2, p.81-7, 2008.

VIEIRA, F.J. Uso e diversidade dos recursos vegetais utilizados pela Comunidade Quilombola dos Macacos em São Miguel do Tapuio. 2008.124p. Dissertação (Mestrado em Desenvolvimento e Meio Ambiente) Universidade Federal do Piauí, Teresina. 